\title{
Why Quitting Double-degree Programs: Students' Perceptions in China
}

\author{
Chuying Ou ${ }^{1}$, Huiyu Zhang ${ }^{1}$, Manjing Pan $^{1} \&$ Zhijian Dai ${ }^{1}$ \\ ${ }^{1}$ School of English and Education, Guangdong University of Foreign Studies, Guangzhou, China \\ Correspondence: Chuying Ou, School of English and Education, Guangdong University of Foreign Studies, 178, \\ Waihuan Donglu, Guangzhou Higher Education Mega Center, Guangzhou 510006, China. Tel: 86-203-932-8036. \\ E-mail: chuying.ou@ foxmail.com
}

Received: October 22, 2018

Accepted: November 9, 2018 Online Published: November 26, 2018

doi:10.5539/hes.v9n1p22

URL: https://doi.org/10.5539/hes.v9n1p22

\begin{abstract}
Around the world, colleges have been providing opportunities for students to participate in double-degree programs. In the past 30 years, double-degree education at tertiary level has been developing fast in China. While many studies focused on its positive effects, little attention was paid to its shortcomings. Through a focus group interview of five undergraduates from a Chinese university, this study revealed some underlying deficiencies of China's double-degree education. The interview comprehensively uncovered participants' motives, expectations, difficulties and reasons for quitting with regard to their double-degree programs. Colleges' failure to live up to expectations (i.e., quality of courses, teachers, job prospects) and students' lack of external support were found to be the main causes that led students to cease their studies. School policies and personal reasons also contributed to their decisions. This research provides advice for future curriculum planning and management of double-degree education from the perspectives of students, teachers and universities.
\end{abstract}

Keywords: double-degree education, undergraduate, China, qualitative study

\section{Introduction}

Nowadays, colleges around the world offer their students opportunities to participate in double-degree programs in order to obtain a second degree. Double-degree education is thought to have satisfied the need of interdisciplinary talents and all-round developed individuals (Chen, Qi, \& Liu, 2007). China started to provide double-degree education in 1980s, which has developed significantly in the past 30 years. Double-degree education has become a regular part of China's curriculum system in tertiary level (Li, 2009).

Lots of researchers have discussed and revealed the significance and benefits of double-degree education, but few of them focused on the existing problems of it. Actually, in some colleges, the number of double-degree graduates has been decreasing, and one of the major reasons is that some students decided to quit their double-degree programs halfway (Mai, 2006). The problem continued to catch public attention as it was reported that in two universities in Guangdong province, half of the students who had taken part in the programs gave up in the end (Tan, Liu \& Feng, 2012). This research, therefore, aims to find out why students dropped out of double-degree programs, which may help to figure out the possible problems of double-degree education. We conducted a focus group interview involving five college students in China, in which they were asked about reasons why they quitted the programs.

\section{Literature Review}

Across the world, researchers proved that a second degree can bring more opportunities in employment sectors as well as a higher earning (e.g., Del \& Hersch, 2008; Hemelt, 2010; Roksa, 2005). Other researchers tried to discover the career destination (Mannix, Harrison, \& Sumsion, 2013), program design (Hunger, Werner, \& Ekadiyanto, 2013) and identity construction of students (Baldry, Märtsin, \& Eivers, 2018) in terms of double-degree education.

In China, double-degree education has gained increasing attention and is widely thought to be a good way to foster interdisciplinary talents. Scholars have discussed many of its benefits, showing a positive attitude towards it. For example, it was found that undergraduates with double degrees are more likely to pursue graduate education or get employed after graduation, and have 13.3\% higher earnings from their first jobs (Ma, 2013). 
Liang, Lv, and Fan's (2006) research indicates a same trend that undergraduates who have obtained double degrees have broader horizons which make them more competitive in the job market.

Though double-degree education is generally proved to be beneficial, what should be noticed is that not all the students would successfully finish their studies. Studies have pointed out that due to reasons like high pressure and lack of time, some double-degree students wanted to quit or had already quitted their programs (Mai, 2006; Wang, Ni, \& Guo, 2008). L. Xu, Zhong, Wu and Hua (2010) have summarized four main problems of double-degree programs. First of all, the teaching of double-degree courses was sometimes blind and random, which means teachers did not well integrate knowledge from different professions, neither did they follow certain rules of knowledge forming and transforming. In addition, some colleges did not provide students with enough opportunities to choose a second degree, and some of the double-degree programs did not result in good teaching effects and qualified graduates. Furthermore, there is still no official document in China which specifically supervises the management of double-degree education. There is no effective quality monitoring system in colleges as well. The lack of necessary guidance and thorough research of training plan, as well as a heavy studying burden upon students' first degrees, all added hardship to effective teaching and management of double-degree education (Bian, 2010).

It can be seen that most of the problems were proposed from the perspectives of universities, but what students themselves think of their choosing or quitting double-degree programs remains unknown. M. Xu's (2009) study particularly investigated the need and degree of satisfaction of non-English majors who chose English as a second degree. Using a questionnaire as the main research tool, her study involved seven colleges and more than 900 students. Surprisingly, almost $40 \%$ of the students were uncertain or dissatisfied towards double-degree programs, and more than half of them were discontent with the textbooks used in the courses. M. Xu later conducted interviews with students being unsatisfied with the programs. She found that dissatisfaction existed because benefits of such studies were not clear during the process and students were unsure about whether they could reach their goals. Besides, studying another degree brought negative effect on their first degrees because it took up much of their free time. Nevertheless, M. Xu's study has some limitations since she did not depict the reasons in detail.

Overall, deficiencies of double-degree education were not given due attention. Even fewer studies tried to expose problems by discovering students' perceptions. Therefore, it remains unknown whether problems perceived by students are the same as what the researchers have summarized by examining the program design and related policies. This research aims to figure out the possible deficiencies of double-degree education by interviewing five college students who gave up their double-degree programs. We decided to conduct a focus group interview with the five participants. The research questions are shown below:

1) What were the motives and expectations that prompted the five students to participate in double-degree programs?

2) What were the difficulties and reasons that led the five students to quit their double-degree programs?

\section{Methodology}

\subsection{Focus Group Interview}

We mainly used focus group interview as the research method. Focus group interview originated from group interviews of sociology and the oral history studies of history. A focus group is, according to Lederman (Thomas, MacMillan, McColl, Hale \& Bond, 1995), "a technique involving the use of in-depth group interviews in which participants are selected because they are a purposive, although not necessarily representative, sampling of a specific population, this group being 'focused' on a given topic". There are several advantages of focus group interview. First, a focus group has the ability to generate data based on the synergy of the group interaction (Green, Draper \& Dowler, 2003). Second, focus group interview can gather a large amount of data in a relatively short time span. It is time-saving and high-efficient. Third, participants are encouraged to communicate with each other, not just with the researchers. Therefore, researchers can regard the interview as a research object and observe the interaction among participants to get more information.

\subsection{Research Site and Participants}

The research was conducted in a university located in Southern China. Double-degree programs in this university usually last for four years (counting from the beginning of first-degree study). Only sophomores are allowed to apply for a double-degree program. The program requires a total of 60 credits, including graduation thesis credit. Courses of double-degree programs are compulsory and students need to complete all the courses during the third to eighth semesters. Five undergraduates in this university took part in our interview. 
Table 1. General Information of the Participants

\begin{tabular}{llllll}
\hline & Sun & Guan & Cai & Xie & Zheng \\
\hline Double degree & Finance & Finance & Finance & Accounting & Finance \\
Grade & Junior & Sophomore & Junior & Junior & Junior \\
\hline
\end{tabular}

Table 1 displays the basic information of the five participants: Sun, Guan, Cai, Xie and Zheng. All of them were studying English and Education as their first degree. Everyone except Xie learnt Finance as a second degree. Xie chose to study Accounting. They were chosen as the participants due to the following three reasons. Firstly, they were friends of the researchers and this laid a good foundation for the reliability of the study, as they were willing to tell us their own stories. Secondly, all of them had been studying a second degree but gave up, which quite fits our research aim. Finally, their double-degree study lasted for more than one year, which means they had rich experience and deep understandings of the programs. This would contribute a lot to our research.

\subsection{Data Collection}

The interview was conducted in a university classroom. Four interviewees took part in the interview in person and one interviewee participated through live broadcast. Before the interview, the research moderator informed the participants of the research topic and promised to keep their information confidential. Participants were asked about information of the following four aspects: their motives for pursuing a second degree, their expectations for the double-degree programs, the difficulties they met and the reasons why they quitted their programs. To allow participants to better express themselves, the interview was conducted in Chinese. It lasted for 80 minutes and a voice recorder was used to record the whole process while researchers were taking notes. Researchers asked questions and the five participants answered one after another.

\subsection{Data Analysis}

All the content of interview was transcribed. We complemented the transcripts with the observational notes taken during the interview and summarized notes written immediately after the interview. Then, we discussed and sorted out the text. Code analysis was used to analyze the data.

Table 2. Coding of the Transcript

\begin{tabular}{|c|c|c|}
\hline Preliminary Codes & Category Codes & Concept Codes \\
\hline Learn new knowledge and experience; & Knowledge and horizons & Motivations \\
\hline Change ways of thinking; & Interest & \\
\hline Follow suggestions from family; & Career choice & \\
\hline \multicolumn{3}{|l|}{ Know more about themselves; } \\
\hline \multicolumn{3}{|l|}{ Bring better career prospects; } \\
\hline \multicolumn{3}{|l|}{ Be interested in the second degree; } \\
\hline \multicolumn{3}{|l|}{ Be uninterested in the first degree. } \\
\hline Teachers teach well; & Courses & Expectations \\
\hline Students are in a good state in class; & Teachers & \\
\hline Students can get a satisfied job; & Satisfied jobs & \\
\hline Students can improve their abilities. & Abilities & \\
\hline The courses are boring and too difficult; & Courses & Difficulties \\
\hline The curriculum designs are irrational; & Teachers & \\
\hline $\begin{array}{l}\text { Teachers are not fully responsible and qualified; } \\
\text { There are few friends in classes of the programs. }\end{array}$ & Interpersonal relationships & \\
\hline There is difficulty in time management; & Dissatisfied expectations & Reasons for \\
\hline The lessons are not suitable; & Lack of external support & quitting the \\
\hline There is difficulty in finding a related job; & School policies & programs \\
\hline School has established new policies; & Personal reasons & \\
\hline There is disapproval from parents; & & \\
\hline Friends quit the program. & & \\
\hline
\end{tabular}

The code analysis went through three-code analysis-three levels of codes. Table 2 illustrates the codes of each category. In the first-round code analysis, we read the transcription several times to sort out the key words and phrases and got the preliminary codes. Later in the second-round code analysis, we looked for commonality in the preliminary codes and then classified them into category codes. In the last round, we discussed the classification of the data sets and combined some of the category codes into a broader aspect to form concept 
codes. We had read over our transcription to ensure that the concept codes could fully illustrate the data.

\section{Findings}

\subsection{Motives and Expectations}

\subsubsection{Motives}

We found out three major motives of the participants to study a double-degree program. First and foremost, they mentioned the merits of accumulating more knowledge and broadening their horizons. The second degrees they chose were all scarcely pertinent to their first degree, so they were helpful in expanding the students' scope of knowledge, for instance:

First of all, I want to learn some subject knowledge which is different from my own major. It's kind of like a supplement to my prior knowledge. Secondly, I'd like to alter my thinking pattern, because my major belongs to liberal arts. Pursuing a degree more related to natural science is likely to help me explore new ideas. (Sun)

The second motive lies in interest. The majority of the interviewees reported that they were interested in their second degrees before they actually received the courses and knew further about the programs. However, from the wording they used to depict their so-called interest, such as "I thought", "I assumed", it can be inferred that they didn't have a clear understanding of the subjects they were going to learn, only to make decisions based on instinct. For example, Cai described the reason why she decided to learn finance:

Actually, before I got to know more about finance, I thought I was interested in finance and economics. I didn't know what I truly liked, because I hadn't been exposed to other subjects...But you don't know what other subjects are like until you really get exposure to them, so I got more curious about what things could be like when you viewed from other perspectives. (Cai)

The third factor accounting for their decision is related to career choice. They either wanted to do the jobs related to their second degrees or they disliked the occupations related to their first degree. Their decisions were also affected by the job prospects the second degree may bring. Since the interviewees mainly chose finance or accounting, it can be seen that they prefer a degree which was seemingly more competitive in the job market. In the following excerpt, Guan directly pointed out the advantages of learning finance compared with education:

In addition, compared with getting a diploma in English and Education, you'll certainly be more competitive when applying for a job, if you can get a diploma in finance. (Guan)

To summarize, the leading factors that led the participants to learn a second degree are knowledge, interest and career choice.

\subsubsection{Expectations}

The focus group interview also centered on the participants' expectations of double-degree programs. The first expectation is pertinent to academic expectations, including that of courses and teachers. For example, Sun explained how she looked forward to the teachers and courses in her double-degree program which should be more interesting:

I expected the lecturing of the teachers would have been funnier than that of the teachers of my first degree. At least they shouldn't be worse than the teachers of my first degree. I also hoped that I could have been more interested in the courses and willing to accomplish the tasks or assignments. (Sun)

Another expectation is about external bonuses, such as opportunities for satisfied jobs and further study, as well as improvement of more abilities. Example can be found in Zheng's case, as she expected the program to bring her benefits in applying for a postgraduate project:

If I could get the diploma of finance, it might help me to apply for a postgraduate program on finance after graduation. I am quite interested in finance, so I hope to obtain more knowledge about it. Another reason is that my original major is English and Education, which is more of a liberal-art major, so I want to study another degree to foster my logical thinking. (Zheng)

As is revealed above, the participants' expectations on double-degree programs were generally high. It can be inferred that if the courses cannot live up to their expectations, they might feel disappointed and lose confidence to tackle difficulties. This may further trigger their tendency to quit.

\subsection{Difficulties and Reasons for Quitting}

\subsubsection{Difficulties}

The second research question deals with the difficulties students came across when they were pursuing a double 
degree. The first barrier is about the courses, including boring course content, excessive level of difficulty, and unreasonable course settings. These factors were reflected in Sun's complaints:

Those courses are filled with theories and they were even not as intriguing as my first degree...Some courses are too complex for students who originally study liberal arts. Besides, I also think the course settings are not so reasonable. That is to say, there are only two courses in sophomore year, but there are far more courses in junior year. (Sun)

The second obstacle is related to the course teachers who were irresponsible and unprofessional. It was surprising that most of the interviewees had a negative impression on the course teachers. Sun reported that one of her teachers was "so irresponsible that he used the PPT designed ten years ago and he didn't update any contents". Zheng also mentioned that the teachers were "not as good as I had imagined".

The third hindrance, which is easily neglected, lies in interpersonal relationships. We realized from the interview that because a double-degree class was usually reconstructed, the vast majority of students didn't know each other beforehand. At the same time, a double-degree class often had no or very few extracurricular activities, which was quite different from a normal class. Owing to this, students' unfamiliarity with each other caused the lack of peer support and reciprocal help. Zheng shared with us how sad she was when she found that the only learning partner dropped out of the program:

My best friend in my double-degree class quitted the course, and I was not so familiar with other classmates in my double-degree class. So there was no one for me to turn to for help, which was quite excruciating. I felt so desperate and this incident magnified all the difficulties I had met. I felt like this was the straw that broke the camel's back. (Zheng)

Most difficulties the interviewees had met were related to their original expectations. Failure to fulfill their expectations was the main cause of their quitting the programs.

\subsubsection{Reasons for Quitting}

The last key research aim is figuring out the reasons why they quitted the program. Although specific reasons might vary from individual to individual, there are some shared reasons that shed light on our research.

First and foremost, dissatisfied expectations account for most interviewees' withdrawal from double-degree programs. As is stated before, most of them held very high expectations for courses, teachers and job prospects, yet these expectations were not met. Thus, the discrepancy between the ideal and the reality could strike them badly. Guan felt especially disappointed when she found that her second degree in finance actually did not bring any advantages to her when she was seeking jobs:

When I went to the job fair, I felt utterly desperate, because even if you have a second degree in finance, the employers won't consider you, thinking that you're just a layman. (Guan)

Another crucial reason is lack of external support, such as parental support or peer support. For some interviewees, their decision-making could be easily distracted or affected by others. For example, Zheng told us how her mother and classmate influenced her to give up the program:

My mom kept telling me how good it was to be a teacher. She told me that even if I succeeded in working in a bank, it would be not as good as being a teacher. But the most important reason is that the classmate that supported me all along quitted her double-degree program. And I felt like I had lost my last glimpse of hope, and I couldn't soldier on. (Zheng)

Zheng was prone to give up when she felt she did not win support from parents in terms of career choice. What's worse was that her learning partner dropped out of the program. It significantly weakened her will to continue the program. Apart from these two factors, school policies also account for some interviewees' decisions. For instance, some students dropped out of the programs because they learnt that from 2015, students who get 30 credits can get a certificate even if they haven't finished the course or the dissertation. Other students quitted the programs because they were not allowed to learn a second degree while engaging in an exchange student program. Other reasons are mainly personal reasons including poor time management, tight schedule, and mismatch between courses and cognitive level.

\section{Discussion and Implications}

\subsection{Discussion}

Previous work has portrayed the significance, existing problems, as well as tactics for improvement about double-degree programs (Bian, 2010; Chen et al., 2007; Li, 2009). However, few of them explored students' 
perceptions of such programs. The current study empirically identified the motives and expectations that prompted students to pursue a second degree, and examined the difficulties and reasons that caused students to quit their double-degree programs. Results of this study support what has been found in previous research that knowledge, interest and employment are paramount motives for students to participate in double-degree programs (e.g., Mai, 2006; M. Xu, 2009). What we have additionally found is that students showed high expectations for the courses, teachers, as well as increased job opportunities the program may bring.

The study has revealed the kinds of difficulties that deprived the participants of their interest, patience and persistence in acquiring a second degree. They involve difficult curriculum content, inappropriate curriculum planning, irresponsible and unprofessional teachers, and alienated interpersonal relationships. Students finally decided to quit the double-degree programs because of unfulfilled expectations (i.e., courses, teachers, job prospects) and lack of external support. Students often look forward to diverse classroom instruction with active interactions and atmosphere (M. Xu, 2009), so it is reasonable that if the programs fail to meet students' wishes, they will become so disappointed and generate the thought of quitting double-degree programs.

Poor time management, tight schedule and mismatch between courses and cognitive level, also turned out to be the contributing factors of students' withdrawal from double-degree programs. Wang et al. (2008) pointed out that the academic disparities between the first and second degrees, high pressure and lack of time are all the difficulties students may come across in double-degree programs. This study accords with their research but adds more factors that may make the students less motivated and even give up the programs, such as alienated interpersonal relationships and lack of external support.

Among those factors, there is one that has rarely been discussed: the limited contribution of double-degree programs to job opportunities. Mai (2006) found out that some students abandoned the chance of learning a second degree because they realized that courses aimed at improving foreign language skills or computer skills were far more beneficial than double-degree programs. Indeed, we found that the advantage of double-degree programs is not as considerable as that of some certificates. Participants thought the value of double-degree programs lies in expanding knowledge scope rather than in directly bringing more job opportunities. In fact, owing to the lower criteria for admission to double-degree programs, more and more students have a chance to take part in the programs; this kind of widely universal "elite education" may have undermined the unique advantage of double-degree programs (Mai, 2006). Perhaps this is why obtaining a second degree does not bring the expected benefits in job-hunting. Students may eventually turn to other helpful ways to increase the possibilities of employment, such as enrolling internships, preparing certificates in certain fields or enrolling in the postgraduate entrance examination. This result is different from a previous study which indicates that double-degree programs could bring obvious superiority in further study and employment, as well as a $13.3 \%$ increase in income (Ma, 2013).

Another unanticipated finding was that lack of external support also contributed to students' quitting double-degree programs. Support from peers and parents turned out to be essential in helping students finish the programs. During the learning process, students are the confused and struggle-filled ones (Baldry et al., 2018), and that's why external support becomes so vital.

\subsection{Implications}

We have drawn some implications for students, teachers and universities. First of all, students are strongly recommended to consider carefully about the value of double-degree programs. Students need to compare the functions of double-degree programs, short-term training programs and job-oriented certificates, and decide whether learning a second degree is a better choice. After resolving to engage in a double-degree program, students should ponder which specific degree they should choose. Overriding priority should be given to whether they are interested in the study of certain degree and whether they are able to study it well. It is important for students to be well aware of their own strengths and limitations before choosing a second degree.

Secondly, teachers are supposed to give more guidance and suggestions when students are choosing their second degrees. They can talk with the students about the ability needed for certain double-degree programs and check whether students reach the standards. In this way, students can have a better understanding and be able to make a wise choice. When delivering lessons in double-degree programs, teachers should pay attention to students' level differences. Students enrolled in the double-degree programs usually come from different institutes. Some of them can catch up with teachers easily, as the courses are closely related to what they have learned. However, students who lack basic knowledge may find it difficult to follow the courses. Thus, teachers should be aware of such level differences and make a balance in content delivery.

Finally, in terms of universities, we recommend that activities should be organized to construct a more united 
class where students could feel a sense of belonging. A united and familiar class may endow students with good interpersonal relationships. In this way, when students run into learning difficulties in studies, they may be more willing to persist because of the support from classmates. Regarding admissions policy, there should be some requirements for admission to double-degree programs. This includes reaching a certain score in related subjects so that students can prove that they are able to handle the programs. For example, if students want to be enrolled in the accounting program as a second degree, they should at least have a good grade in mathematics in the college entrance examination. At the same time, it is advised that the GPA requirement for getting admission to double-degree programs should be raised. This again helps to ensure that students have enough learning ability in studying a second degree which may be so different from their first ones. Reference books should be also provided for students before the programs begin. This will give them an opportunity to judge whether the subjects are too difficult for them.

\section{Conclusion}

This paper tried to figure out why students quitted their double-degree programs through a focus group interview conducted in a university in southern China. We found that there are two main reasons. The most important one is that the double-degree education received by the students did not meet their expectations. The high expectations from students included quality of courses, teachers and job prospects, etc. However, the discrepancy between the ideal and reality primarily caused them to give up the double-degree programs. The other crucial reason is lack of external support. The participants could not get enough support from their parents and friends, which made them feel upset. Other than the two main reasons, school policies and personal reasons including poor time management, tight schedule, and mismatch between courses and cognitive level, also account for their withdrawal from the programs.

The study also gave some suggestions for the implementation of double-degree programs. Obviously, successful completion of the program relies on the joint efforts of students, teachers and universities. To be specific, students are advised to be more cautious when choosing a double-degree program, taking both interest and capability into account. Teachers are supposed to provide more guidance to get students familiar with the programs, and pay attention to their level differences in class. In terms of universities, they should help to create a closer relationship among participants of the same double-degree program and at the same time raise the admissions requirements.

Nevertheless, since our study only involved five students in a specific university in Southern China, our conclusion may not fully apply to other colleges. We suggest future researchers conduct studies involving a larger scale of students in China. In this way, more common problems may be revealed and policy makers are able to get valuable information about how to improve the quality of double-degree programs.

\section{Acknowledgments}

Financial support for this study was provided by Student's Platform for Innovation and Entrepreneurship Training Program from Guangdong University of Foreign Studies. We would like to thank Prof. Hailing Wei from Guangdong University of Foreign Studies for her valuable advice on the earlier drafts of the paper.

\section{References}

Baldry, S., Märtsin, M., \& Eivers, A. (2018). Traveling Without a Destination ? A Dialogical Analysis of Professional Identity Construction Among Australian Double Degree Psychology Students. Identity, 18(2), 94-108. https://doi.org/10.1080/15283488.2018.1447483

Bian, S. (2010). Wanshan fuxiu, shuangxuewei jiaoyu jiaoxue guanli gongzuo de sikao (Improving the teaching and management of double degree studies). Jiaoyu Tansuo(Education Exploration), 2, 95-96.

Chen, X., Qi, L., \& Liu, Y. (2007). Shuangxuewei benke jiaoyu yanjiu (A research on double-degree education of ungergraduates). Zhongguo Gaojiao Yanjiu (China Higher Education Research), 2, $26-28$. https://doi.org/10.3969/j.issn.1004-3667.2007.02.008

Del, A. F., \& Hersch, J. (2008). Double your major , double your return ? Economics of Education Review, 27, 375-386. https://doi.org/10.1016/j.econedurev.2007.03.001

Green J., Draper, A., \& Dowler, E. (2003) Short cuts to safety: risk and 'rules of thumb' in accounts of food choice. Health, Risk and Society, 5(1), 33-52. https://doi.org/10.1080/1369857031000065998

Hemelt, S. W. (2010). The college double major and subsequent earnings. Education Economics, 18(2), 167-189. https://doi.org/10.1080/09645290802469931

Hunger, A., Werner, S., \& Ekadiyanto, F. A. (2013). Towards an Automated tool for Assisting the Design of 
Double Degree Programs. Procedia - Social and Behavioral Sciences, 102, 228-235. https://doi.org/10.1016/j.sbspro.2013.10.737

Li, L. (2009). Woguo daxue fuxiu yu shuangxuewei gaige de huigu yu fenxi (A review and analysis of the reform of minoring and double-degree programs in China). Zhongguo Gaojiao Yanjiu (China Higher Education Research), 1, 60-62. https://doi.org/10.16298/j.cnki.1004-3667.2009.01.016

Liang, L., Lv, L., \& Fan, W. (2006). Yige peiyang fuhexing rencai de gean fenxi: Huazhong keji daxue yingyu-tongxin shuangxuewei peiyang moshi yanjiu (A case study on inter-disciplinary personnel dual-degree program: Research of 2001-entry E-T majors at HUST). Gaodeng Jiaoyu Yanjiu (Journal of Higher Education), 27(3), 79-83.

Ma, L. (2013). Shuangxuewei shuanghuibao? Jiyu quanguo gaoxiao biyesheng jiuye diaocha de shizheng yanjiu (Double Major, Double Earnings? An Empirical Research on National College Graduates' Employment). Jiaoyu Fazhan Yanjiu (Research in Educational Development), 21, 18-23. https://doi.org/10.14121/j.cnki.1008-3855.2013.21.008

Mai, D. (2006). Huanan ligong daxue jinnian shuangxuewei biyesheng jiuye qingkuang de diaocha yu fenxi(A survey of the employment situation of double-degree graduates in South China University of Technology). Huanan Ligong Daxue xuebao(Journal of South China University of Technology), 8, 93-96. https://doi.org/10.3969/j.issn.1009-055X.2006.z1.028

Mannix, J., Harrison, L., \& Sumsion, J. (2013). Transition to work and the career destinations of double degree nurses. Contemporary Nurse, 45(1), 64-78. https://doi.org/10.5172/conu.2013.45.1.64

Roksa, J. (2005). Double Disadvantage or Blessing in Understanding the Relationship Between College Major and Employment Sector. Sociology of Education, 78, 207-232. https://doi.org/10.1177/003804070507800302

Tan, X., Liu, R., \& Feng, H. (2012). Half of the program students gave up double-degree study. [Webpage]. Retrieved from https://roll.sohu.com/20120606/n344832962.shtml

Thomas L., MacMillan, J., McColl, E., Hale, C., \& Bond, S. (1995) Comparison of focus group and individual interview methodology in examining patient satisfaction with nursing care. Social Sciences in Health, 1(4), 206-219.

Wang, X., Ni, S., \& Guo, K. (2008). Shuangxuewei benkesheng peiyang: linian, moshi yu celue(The idea, mode and strategies of cultivating double-degree ungergraduates). Zhongguo Gaojiao Yanjiu (China Higher Education Research), 12, 27-30. https://doi.org/10.16298/j.cnki.1004-3667.2008.12.017

Xu, L., Zhong, E., Wu, A., \& Hua, J. (2010). Shuangzhuanye Fuhexing Rencai Peiyang Moshi Chonggou Yanjiu (A Study on Reconstructing the Pattern of Cultivating Talents through Double Major). Gaodeng Nongye Yanjiu(Higer Agricultural Education), 8, 65-67. https://doi.org/10.13839/j.cnki.hae.2010.08.024

Xu, M. (2009). Yingyu shuangxuewei xuesheng zhi xuqiu yu manyidu: Guanyu Wuhan qixiao shoulun lianhe banxue zhuangkuang de diaocha fenxi (The need and degree of satisfaction of students with a double major in English: A survey of seven joint-running colleges in Wuhan). Gaodeng Gongcheng Jiaoyu Yanjiu(Research in Higer Education of Engineering), 2, 133-136.

\section{Copyrights}

Copyright for this article is retained by the author(s), with first publication rights granted to the journal.

This is an open-access article distributed under the terms and conditions of the Creative Commons Attribution license (http://creativecommons.org/licenses/by/4.0/). 